 \\ Original Article \\ Print ISSN: 2636-7378 | Online ISSN: 2651-5865
}

pg. 293

\section{Stroke Perception and Response amongst Elderly Persons in Benin, City, Nigeria}

\author{
Odiase $\mathbf{F E}^{1^{*}}$, Kayode-Iyasere $\mathbf{E}^{2}$ \\ ${ }^{1}$ Department of Medicine, College of Medical Sciences, University \\ of Benin, Benin City, Nigeria. \\ ${ }^{2}$ Department of Medicine, Central Hospital, Benin City. \\ doi) : https://doi.org/10.46912/jbrcp.162
}

\section{*Correspondence:}

Odiase FE : francisodiase2000@hotmail.com

\begin{tabular}{|l|l|}
\hline $\begin{array}{l}\text { Article } \\
\text { information }\end{array}$ & $\begin{array}{l}\text { Date Submitted: 16/4/2020 } \\
\text { Date Accepted: 1/5/2020 } \\
\text { Date Published: June, 2020 }\end{array}$ \\
\hline
\end{tabular}

\begin{abstract}
Theories on health behavior have recognized perceived risk as an essential factor in the adoption of a healthy life-style, however, little is known about stroke risk perception and response to stroke in the elderly population of Nigeria. Ageing being the most important unmodifiable risk factor for stroke, this study aims to determine the predictors of perception of stroke risk and response to stroke in the elderly This was a cross-sectional study, which involved a multi-stage random sampling, recruiting one hundred and sixty individuals 65years and older. Interview was by face to face using a questionnaire to determine, demographics, knowledge of stroke risk, perception of stroke risk and response in the event of stroke. Multiple logistic regression models were used to analyze predictors of dependent variables. Only $32.5 \%$ of participants had an accurate perception of stroke risk while $30.6 \%$ would consider taking a patient to hospital in the event of a stroke. Increasing age $(P=0.001)$, the female gender $(P<0.05)$, having two or more risk factors for stroke $(P=0.001)$ and attending two or more specialized clinics $(P=0.001)$ were significant predictors of wrong perception of stroke risk and inappropriate respond in the event of stroke. The elderly are at risk for stroke, but sadly with increasing age and additional risk factors for stroke, majority have a wrong perception of stroke risk and would respond inappropriately in the event of a stroke. It might be necessary to run stroke campaigns that are targeted and appropriate to the elderly, involving continuous intermittent repetitions.
\end{abstract}

Keywords: Elderly, Perception, Predictors, Response, Stroke

\section{INTRODUCTION}

A person's perception of health risk is a recognized issue when goals of primary and secondary prevention of a disease are expressed. It is generally held that efforts to improve public awareness of stroke, its risk factors and warning signs would translate to prompt response in the event of stroke and participation in preventive measures. Although improving stroke knowledge is necessary, it is not alone sufficient to determine a course of action in stroke care. Persons would adopt healthier behavior, when they perceive a personal risk or susceptibility to a disease. The greater the perception of risk the greater the possibility of engaging in behavior to decrease the risk, conversely poor compliance to recommended health behaviors is associated with lower 
perceived risk.$^{1,2,3,4}$ Ageing is a very important risk factor for stroke. ${ }^{5,6,7}$ It is suspected that in the next decade, stroke deaths will almost double mainly as a result of increase in the proportion of older people. ${ }^{8,910}$ There have been numerous advances in the prevention and treatment of stroke, ${ }^{11,12}$ but in spite of these the number of stroke continues to rise as a result of the ageing demographics of most populations. ${ }^{13}$ The world health organization has reported that stroke is the second leading cause of mortality and disease burden among adults aged sixty years and over. ${ }^{14,15}$ The increase in the number of stroke cases in the elderly would increase the burden of this disease significantly and may overwhelm the limited resources available for health care. ${ }^{16}$ Good knowledge of stroke and accurate perception of stroke risk would ensure compliance to preventive measures of stroke and facilitate appropriate prompt response in the event of a stroke. ${ }_{17,18,19,20}$ Studies have shown that the older individuals have the least knowledge of stroke risk factors, warning signs and also a wrong perception of stroke risk..$^{21,22,23,24,25 .}$ The consequence of this is that, while older people are particularly vulnerable to stroke they might not participate fully in either primary or secondary stroke preventive measures and may not act on symptoms of stroke in themselves or in others.

We are not aware of any study in Nigeria that have evaluated the perception of stroke risk and response to stroke amongst the elderly. Given that older people are the most at risk demographic group for stroke, this study aims to determine the predictors of perception of stroke risk and response in them.

\section{MATERIALS AND METHODS}

This study was done in Benin City, the capital of Edo state, with an estimated population of 1.5 million inhabitants. It was a community based observational cross-sectional survey involving persons aged 65years and above who were willing to participate in the study. Individuals who have had stroke or those with a relative with stroke, those with debilitating ailments, doctors, pharmacists, nurses or employee of the healthcare system where excluded from the study. This study was conducted from February 2018 to April 2019. We had a 3-staged random sampling method which involved, community sampling, household sampling and household resident sampling. The procedure for collecting information was by face to face interview conducted by well-trained interviewers who had a two weeks training on data collection in order to minimize inter-observer variability and were conversant with English and the local language. In other not to exclude workers, interviews were conducted at weekends and weekdays after working hours. Five communities in the state capital (Benin City) were randomly selected from a list of communities in our locality. Household sampling was done by the random-walk method, in which a random starting point is chosen from the particular community and pre-specified direction (right-ward in this study) was followed by interviewers ${ }^{26}$ Each household was to contribute one participant. If a household had more than one potential participant, then a simple random method using cards labeled yes or no was used to select one participant. If in the contacted household no respondent was found, or there is refusal to participate then the next house is visited. If the eligible person is not around, another interview is scheduled. The survey instrument was a structured questionnaire which was designed for this work and based on a literature review of earlier studies concerning person's knowledge, perception and response to stroke. . $2,22,23,24,27,28$ We tested the questionnaire in a pilot study with a sample of ten persons with minor changes in wording based on the findings of the pilot study. The questionnaire was divided into 3 sections. The first section asked if they were on treatment for any medical condition, number of pills taken every day and the number of specialized consultations made on this regard. In the second section participants were asked to mention at least one risk factor of stroke, they were asked if they perceive/think they can have a stroke and also to mention the response/action to take if stroke is suspected in a hypothetical case (sudden loss of speech, or weakness of a half of the body). The third section collected data on the socio-demographics of each participant including the gender, age, educational status, marital status, occupational status, and numbers of persons at home. At the end of the interview each participant was informed about risk factors of stroke, signs of stroke, accurate perception of stroke risk and the appropriate response in the event of a stroke. The data collected were later recorded for analysis in logical categories. The outcome measures where, good stroke knowledge which was the ability to mention one or more risk factor of stroke, accurate perception of stroke risk, which is that participants been elderly are at risk of stroke and 
appropriate response to stroke which is immediate transfer of the patient to hospital. Ethical approval was obtained from the ethics and research committee central hospital Benin City. The statistical analysis was performed using SPSS version 21. Continuous variables were presented using means, median, standard deviation and interquartile range with comparison using the studentt-test. Frequency and percentages were used to summarize categorical variables with chi-square used to assessing the association between the variables. Logistic regression analyses was used to examine the effects of several independent variables and the three dependent variables of good stroke risk knowledge, accurate perception of stroke risk and appropriate response to stroke. The hypothesis testing were two tailed and significance was $<0.05$.

\section{RESULTS}

A total of nine hundred and sixty households were contacted, five hundred and fifty-eight households declined participating, two hundred and eighteen households were not eligible, while one hundred and eighty four households had at least one person sixty-five years and older. There was incomplete data for twentyfour participants.

One hundred and sixty persons, sixty-five years and older were recruited for the study. About fifty-four percent (86) were females, while the mean age was $77.4(5.4)$ years with an age range of 65 to 85years. Sixty-eight percent (109) of the participants were over 70years old while over $60 \%$ (99) had higher academic qualifications. Majority $(62.5 \%, 100)$ of the participants are married, 56.2\% (90) had three or more persons at home most times, while $40 \%$ (64) were still working either in public settings as contract staff or in private establishment. Fifty-five percent (88) of participants had two or more risk factors for stroke, while $47.5 \%$ (76) are on at least 3 or more tablets every day for their conditions and $36.9 \%$ (59) attends more than two specialized clinics. Sixty-eight (42.5\%) participant mentioned correctly at least one risk factor for stroke, only fifty-two $(32.5 \%)$ had an accurate perception of stroke risk, while in the event of a stroke occurring in them or their relatives, a merely forty-nine $(30.6 \%)$ mentioned immediate transference to the hospital. Table I.

Those aged 65 to 69 years compared to 70 to 74 years and $>75$ years were more likely to correctly mention at least one risk factor for stroke $(70.6 \%$ versus $17.8 \%$ versus $37.5 \% P=0.001)$, had a higher proportion with accurate perception of stroke risk $(52.9 \%$ versus $6.7 \%$ versus $34.4 \% P=0.001$ ), and were more likely to take a stroke victim to hospital in the event of a stroke $(58.8 \%$ versus $2.2 \%$ versus $28.1 \% P=0.001$ ). Table II

Those with higher educational status compared to those with lower were more likely to correctly mention at least one risk factor for stroke ( $48.5 \%$ versus $32.8 \%, P=0.05$ ) and were more likely to take a stroke victim to hospital immediately $(37.4 \%$ versus $19.7 \%, P=0.02)$, The participants with two or more risk factors of stroke compared to those with fewer risks factors, had a lesser proportion with accurate perception of stroke risk (23.9\% versus $43.1 \% P=0.01$ ), and were less likely to take a stroke victim to hospital immediately, $(21.6 \%$ versus $41.7 \%$, $P=0.006$ ). The participants who attended two or more clinics compared with those with fewer attendance, had a lesser proportion with accurate perception of stroke risk. ( $16.9 \%$ versus $41.6 \%$ of $P=0.001$ ) and were less likely to take a stroke victim to hospital immediately $(11.9 \%$ versus $41.6 \% P=0.001)$. Participants that took three pills or more a day compared with those who took fewer, were less likely to take a stroke victim to hospital immediately( $17.1 \%$ versus $42.9 \% P=0.001)$. Table II.

With respect to knowledge of stroke risk factor, the multiple logistic regression analysis showed that two variables were significant predictors for poor knowledge of stroke risk factors including increasing age (OR 0.09 $95 \%$ CI 0.01 to $0.83, P=0.03$ ), having two or more risk factors for stroke (OR $0.22,95 \%$ CI 0.07 to $0.70, P=0.01$ ) while higher educational status (OR 4.83, 95\% CI 1.32 to $17.6 P=0.02$ ) is a significant predictor for good knowledge for stroke risk factors. Gender, marital status, number of persons at home, number of specialize clinic attending, and occupational status and number of pills taken per day, were not predictive of knowledge of risk factors for stroke. Table III

Regarding participants perception of stroke risk, in the multiple logistic regression analysis, increasing age( OR, $0.02,95 \% \mathrm{CI}, 0.002$ to $0.20 P=0.001)$, female gender(OR $0.05,95 \%$ CI 0.01 to $0.52, P=0.001)$, having two or more risk factors for stroke (OR, $0.10,95 \% \mathrm{CI}, 0.03$ to 0.37 , $P=0.001$ ), and attending two or more specialized clinics (OR $0.06,95 \%$ CI 0.01 to $0.30, P=0.00 \mathrm{I}$ ) were significant predictors for wrong perception of stroke risk, while taking three or more pills a day was a significant predictor 
Table I: Demographics and clinical characteristics of the elderly participants $(\mathbf{n}=160)$

Variables
Age categories
65 to 69 years
70 to 74 years
$>75$ years
Total
Gender
Male
Female
Total

Educational status

Primary and secondary (lower)

Tertiary (higher)

Total

\section{n (\%)
$51(31.9)$
45 (28.1)
64 (40)
160 (100)

74 (46.3)

$86(53.7)$

$160(100)$

Occupational status

Retired

Still working

Total

$64(40)$

160 (100)

Marital status

Married

Widowed, Separated, unmarried (Single)

$100(62.5)$

$60(37.5)$

Total

160 (100)

Number of stroke risk factors

$\leq 1$

$\geq 2$

$72(45)$

$88(55)$

Total

160 (100)

Number of specialist clinic attending

$\leq 1$

$\geq 2$

$101(63.1)$

59 (36.9)

160 (100)

Numbers of pills taken per day

$\leq 2$

$\geq 3$

$84(52.5)$

$76(47.5)$

160 (100)

Numbers of persons at home

$\leq 2$

$70(43.8)$

$90(56.2)$

Total

$160(100)$

Summary indicators, to knowledge, perception and response to stroke Good stroke risk factor knowledge

Accurate perception of stroke risk

$52(32.5)$

Appropriate response to stroke

$49(30.6)$

160 (100) 
of accurate perception of stroke risk (OR, $17.595 \% \mathrm{CI}$ 3.47 to $88.2, P=0.001)$. Educational status, marital status, number of persons at home and occupational status were not predictive of perception of stroke risk. Table III Concerning the response of participants following a stroke, higher educational status (OR 7.91, 95\% CI 1.38 to $45.3, P=0.02$ ), was the only significant predictors for an appropriate action in the event of a stroke, while increasing age (OR $0.0495 \% \mathrm{CI} 0.004$ to $0.50 P=0.01$ ), the female gender (OR $0.06,95 \%$ CI 0.01 to $0.79 P=0.03$ ), attending two or more specialized clinics were significant predictors for inappropriate action following a stroke (OR $0.07,95 \%$ CI 0.01 to $0.32 P=0.001)$. The marital status, the numbers of persons at home, the occupational status, the numbers of risk factors for stroke, numbers of pills taken a day, were not predictive of the response in the event of a stroke. Table III.

TABLE II: Response of participants to knowledge, perception and action in the event of stroke

\begin{tabular}{|c|c|c|c|c|c|c|}
\hline Variables & $\begin{array}{c}\text { Correct risk } \\
\text { factor }\end{array}$ & $P$ & $\begin{array}{c}\text { accurate } \\
\text { perception }\end{array}$ & $P$ & $\begin{array}{c}\text { Appropriate } \\
\text { Response }\end{array}$ & $P$ \\
\hline \multicolumn{7}{|l|}{ Age (yrs.) } \\
\hline 65 to 69 & $36(70.6 \%)$ & 0.001 & $27(52.9 \%)$ & 0.001 & $30(58.8 \%)$ & 0.001 \\
\hline 70 to 74 & $8(17.8 \%)$ & & $3(6.7 \%)$ & & $1(2.2 \%)$ & \\
\hline$>75$ & $24(37.5 \%)$ & & $22(34.4 \%)$ & & $18(28.1 \%)$ & \\
\hline \multicolumn{7}{|l|}{ Gender } \\
\hline Male & $30(40.5 \%)$ & 0.64 & $26(35.1 \%)$ & 0.51 & $22(29.7 \%)$ & 0.82 \\
\hline Female & $38(44.2 \%)$ & & $26(30.2 \%)$ & & $27(31.4 \%)$ & \\
\hline \multicolumn{7}{|l|}{ Marital Status } \\
\hline Married & $43(43 \%)$ & 0.87 & $37(37 \%)$ & 0.12 & $30(30 \%)$ & 0.83 \\
\hline Single & $25(41.7 \%)$ & & $15(25 \%)$ & & $19(31.7 \%)$ & \\
\hline \multicolumn{7}{|l|}{ Educational Status } \\
\hline Primary \&secondary & $20(32.8 \%)$ & 0.05 & $16(26.2 \%)$ & 0.18 & $12(19.7 \%)$ & 0.02 \\
\hline Tertiary & $48(48.5 \%)$ & & $36(36.4 \%)$ & & $37(37.4 \%)$ & \\
\hline \multicolumn{7}{|l|}{ Occupational Status } \\
\hline Retired & $42(43.8 \%)$ & 0.70 & $36(37.5 \%)$ & 0.10 & $33(34.4 \%)$ & 0.21 \\
\hline Still working & $26(40.6 \%)$ & & $16(25 \%)$ & & $16(25 \%)$ & \\
\hline \multicolumn{7}{|l|}{ Numbers of risk factors } \\
\hline$\leq 1$ & $39(54.2 \%)$ & 0.07 & $31(43.1 \%)$ & 0.010 & $30(41.7 \%)$ & 0.006 \\
\hline$\geq 2$ & $29(33 \%)$ & & $21(23.9 \%)$ & & $19(21.6 \%)$ & \\
\hline \multicolumn{7}{|c|}{ Number of pills taken per day } \\
\hline$\leq 2$ & $40(47.6 \%)$ & 0.17 & $29(34.5 \%)$ & 0.57 & $36(42.9 \%)$ & 0.001 \\
\hline$\geq 3$ & $28(36.8 \%)$ & & $23(30.3 \%)$ & & $13(17.1 \%)$ & \\
\hline \multicolumn{7}{|c|}{ Number of persons at home } \\
\hline$\leq 2$ & $32(45.7 \%)$ & 0.47 & $23(32.9 \%)$ & 0.93 & $21(30 \%)$ & 0.88 \\
\hline$\geq 3$ & $36(40 \%)$ & & $29(32.2 \%)$ & & $28(31.1 \%)$ & \\
\hline \multicolumn{7}{|c|}{$\begin{array}{c}\text { Number of specialist clinic } \\
\text { attended }\end{array}$} \\
\hline$\leq 1$ & $46(45.5 \%)$ & 0.31 & $42(41.6 \%)$ & 0.001 & $42(41.6 \%)$ & 0.001 \\
\hline$\geq 2$ & $22(37.3 \%)$ & & $10(16.9 \%)$ & & $7(11.9 \%)$ & \\
\hline
\end{tabular}


TABLE III: Multiple logistic regression analysis to predict stroke knowledge, perception and response in the event of stroke

\begin{tabular}{|c|c|c|c|c|c|c|}
\hline Variables & $\begin{array}{c}\text { Correct risk } \\
\text { factor } \\
\text { OR }(95 \% \mathrm{C} \mathrm{I})\end{array}$ & $P$. & $\begin{array}{c}\text { Accurate } \\
\text { Perception } \\
\text { OR(95\%C I) }\end{array}$ & $P$. & $\begin{array}{c}\text { Appropriate } \\
\text { response } \\
\text { OR }(95 \% \text { C I) }\end{array}$ & $P$. \\
\hline \multicolumn{7}{|l|}{ Age } \\
\hline 65 to $69 \mathrm{yrs}$ & 1 & & 1 & & 1 & \\
\hline 70 to $74 \mathrm{yrs}$ & $\begin{array}{l}0.03(0.01 \text { to } \\
0.12)\end{array}$ & 0.001 & $0.02(0.003$ to 0.11$)$ & 0.001 & $0.01(0.001$ to 0.07$)$ & 0.001 \\
\hline$>75 y r s$ & $\begin{array}{c}0.09(0.01 \text { to } \\
0.83)\end{array}$ & 0.03 & $0.02(0.002$ to 0.20$)$ & 0.001 & $0.04(0.004$ to 0.50$)$ & 0.01 \\
\hline \multicolumn{7}{|l|}{ Gender } \\
\hline Male & 1 & & 1 & & 1 & \\
\hline Female & $\begin{array}{l}0.37(0.04 \text { to } \\
3.43)\end{array}$ & 0.38 & $0.05(0.01$ to 0.52$)$ & 0.001 & $0.06(0.01$ to 0.79$)$ & 0.03 \\
\hline \multicolumn{7}{|l|}{ Marital status } \\
\hline Single & 1 & & 1 & & 1 & \\
\hline Married & $\begin{array}{l}1.14(0.41 \text { to } \\
3.20)\end{array}$ & 0.80 & $1.05(0.31$ to 3.54$)$ & 0.94 & $2.20(0.58$ to 8.27$)$ & 0.25 \\
\hline \multicolumn{7}{|l|}{ Education status } \\
\hline Primary \&secondary & 1 & & 1 & & 1 & \\
\hline Tertiary & $\begin{array}{c}4.83(1.32 \text { to } \\
17.6)\end{array}$ & 0.02 & $2.56(0.62$ to 10.6$)$ & 0.196 & $7.91(1.38$ to 45.3$)$ & 0.02 \\
\hline \multicolumn{7}{|c|}{ Occupational status } \\
\hline Retired & $1-$ & & 1 & & 1 & \\
\hline Still working & $\begin{array}{l}1.48(0.46 \text { to } \\
4.71)\end{array}$ & 0.51 & $0.86(0.24$ to 3.16$)$ & 0.82 & $1.22(0.27$ to 5.42$)$ & 0.80 \\
\hline \multicolumn{7}{|l|}{ Number of risk factors } \\
\hline$\leq 1$ & 1 & & & & & \\
\hline$\geq 2$ & $\begin{array}{l}0.22(0.07 \text { to } \\
0.70)\end{array}$ & 0.01 & $0.10(0.03$ to 0.37$)$ & 0.001 & $0.30(0.08$ to 1.18$)$ & 0.08 \\
\hline \multicolumn{7}{|c|}{ Number of pills taken per day } \\
\hline$\leq 2$ & 1 & & & & & \\
\hline 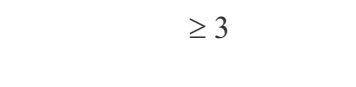 & $\begin{array}{c}3.05(0.90 \text { to } \\
10.3)\end{array}$ & 0.07 & $17.5(3.47$ to 88.2$)$ & 0.001 & $2.04(0.47$ to 8.79$)$ & 0.34 \\
\hline \multicolumn{7}{|l|}{ Number of persons at home } \\
\hline$\leq 2$ & 1 & & 1 & & 1 & \\
\hline$\geq 3$ & $\begin{array}{l}2.34(0.80 \text { to } \\
6.79)\end{array}$ & 0.12 & $0.60(0.16$ to 2.26$)$ & 0.45 & $1.82(0.40$ to 8.25$)$ & 0.44 \\
\hline \multicolumn{7}{|c|}{$\begin{array}{l}\text { Number of specialists' clinics } \\
\text { attended }\end{array}$} \\
\hline$\leq 1$ & 1 & & 1 & & & \\
\hline$\geq 2$ & $\begin{array}{l}1.01(0.32 \text { to } \\
3.18)\end{array}$ & 0.98 & $0.06(0.01$ to 0.30$)$ & 0.001 & $0.07(0.01$ to 0.32$)$ & 0.001 \\
\hline
\end{tabular}




\section{DISCUSSION}

Ageing is an important established risk factor for stroke as a result the older individuals are an important population to target in relation to awareness, risk perception and response to stroke. Knowledge of risk factors for stroke without participation in preventive measures is pointless and recognition of symptoms of stroke is meaningless unless it leads to prompt hospital transfer. Not surprising some studies have shown increased public knowledge of stroke but, in spite of this, delay in assessing care for stroke is common. ${ }^{17,28,29,30,31,32,33}$ Participation in primary or secondary stoke preventive measures, taking action in the event of a stroke depends not only on knowledge of stroke risk factors, recognition of stroke warning symptoms but also on the individual's perception of stroke. It is logical that when persons believe they can suffer a disease (perception), they would be more likely to take actions to prevent it or access treatment promptly in the event of the disease occurring. Conversely unhealthy behavior does result from the belief that one is not at risk or has a low susceptibility to a disease. ${ }^{2,3,4,34,35,36}$ This study showed that in all three outcome measures, over $50 \%$ of respondents were unable to give satisfactory answers, while $47.5 \%$ mentioned correctly one risk factor for stroke, only $32.5 \%$ had an accurate perception of stroke risk while an even lesser proportion of $30.6 \%$ would consider taking a patient to hospital in the event of a stroke. We found that with increasing age, fewer participants responded correctly to knowledge of stroke risk factors, fewer felt they could have a stroke and even fewer considered taking a patient to hospital as the first line of action following a stroke. Increasing age was also a significant predictor of poor knowledge for stroke, wrong perception of stroke risk and poor response to stroke. This unsatisfactory response is quiet worrisome as the risk of stroke increases with age. This would lead to poor participation in preventive measures, could delay transference of either themselves or relative to hospital. The possible explanations could be cognitive decline or reduced social interactions. Several studies have had similar observations while others have found no relationship between these variables. ${ }^{20,21,22,23,25,37}$ We also found that those with higher educational qualifications were significantly more likely to mention risk factors of stroke and would respond appropriately in the event of a stroke, and also predictive of correct response to all three dependent variables. This has been a consistent finding in earlier works. ${ }^{20,21,22,23,25,37,38,39,40}$ The finding in this study is not impressive since with about $60 \%$ of respondents having higher educational status less than $45 \%$ could make appropriate responses. Hence stroke awareness should not be assumed to come on naturally, efforts should be made to inform and educate the elderly on a regular basis in spite of educational status. We did not find any association between gender and knowledge of stroke risk factors, however, after adjusting for the other variables the female gender was a significant predictor for wrong perception of stroke risk and inappropriate response in the event of a stroke. There have been contrasting findings regarding gender and the dependent variables. ${ }^{41,42,43,44,45,46}$ This female response in the event of a stroke may reflect the practice of getting approval from family members before transference to hospital, this should be discouraged as delay could be dangerous. Additionally there is the need to appreciate these aspects of wrong perception to stroke risk, which might be a reflection of the gender's emotions, as the female is not personalizing the disease risk. This study found no association between marital status, number of persons at home, occupational status and the dependent variables.

We have found that those with two or more risk factors for stroke had a significantly lesser likelihood to respond correctly to knowledge for stroke risk, a wrong perception of stroke risk and inappropriate response in the event of a stroke, and after adjusting for other variable, two or more risk factors was a significant predictor for poor stroke knowledge and wrong perception to stroke risk. Aging is an established risk factor for stroke and having addition risk factors has a multiplier effect, consequently this finding is especially troubling. Several other studies have had similar observation. ${ }^{22,23,28,2,29,37,38}$ This finding appeals for a closer scrutiny of the elderly especially those with multiple risk factors as targets for stroke education.

Respondents who took three or more pills for their health conditions were found to be significantly less likely to respond appropriately in the event of a stroke. However after adjusting for other eight independent variables more pill usage was predictive for accurate perception of stroke risk, it is possible that frequent usage of this medications have endeared their interest in their indications and vascular factors. There have been divergent observations from other studies. ${ }^{47,48,49,50,51}$ Our study showed that participants who attended two or more specialized clinics 
had significantly lesser proportion with accurate perception of stroke risk and appropriate response to stroke, additionally it was also significantly predictive for wrong perception to stroke risk and inappropriate response to stroke. This is surprising as it would have been expected, that having more hospital contacts, would facilitate better health information. Studies have similarly shown that the hospital settings were not the main sources of information with regards to stroke., 9,19,20,22,23,2428,30,3839 Health workers should be encouraged to inform and educate the elderly in whatever specialized clinic they attend on the importance of vascular risk as this is a much commoner cause of morbidity and mortality in this group.

\section{CONCLUSION}

The elderly are at risk for stroke, but sadly with increasing age and additional risk factors for stroke, they are less knowledgeable of stroke risk factors, have a wrong perception of stroke risk and would respond inappropriately in the event of a stroke. General stroke campaign covers the majority of the populace, but it might be necessary to run campaigns that are targeted and appropriate to the elderly, involving intermittent continuous repetitions on stroke knowledge, accurate perception and appropriate response in the event of a stroke.

\section{Limitations}

The study had limitations, one of these was the representativeness of the population through the multistage sampling method especially since a list of household was not available for sampling, and as a consequence the widely used random-walk method was used. ${ }^{26}$ Another limitation was the reliance entirely on what participants said regarding their medical care.

\section{REFERENCES}

1. Townend E, Tinson D, Kwan J, Sharpe M: Fear of recurrence and beliefs about preventing recurrence in persons who have suffered a stroke. J Psych Res2006; 61(6):747-755.

2. Janz NK, Becker MH. The health belief model: a decade later. Health Educ Q. 1984; 11:1-47.

3. Stafford L, Jackson H and Berk M. Illness beliefs about heart disease and adherence to secondary prevention regimens. Psych Med 2008; 70 : 942-948.

4. Kaplan MK, Sallis JF, Patterson TL. Health and Human Behavior. New York, NY: McGraw-Hill, Inc; 1993.

5. Go AS, Mozaffarian D, Roger VL, Benjamin EJ, Berry JD, Borden WB, et al. American Heart Association Statistics Committee and Stroke Statistics Subcommittee. Heart disease and stroke statistics - 2013 update: a report from the American Heart Association. Circulation.2013; 127:e6-e245

6. Feigin VL, Lawes CMM, Bennett DA, Barker-Collo SL, Parag V: Worldwide stroke incidence and early case fatality reported in 56 population-based studies: a systematic review. Lancet Neurol 2009, 8(4):355-369.

7. Saposnik G, Cote R, Phillips S, Gubitz G, Bayer N, Minuk J, et al. Stroke outcome in those over 80: a multicenter cohort study across Canada. Stroke. 2008; 39:2310-2317.

8. National Center for Health Statistics. Health, United States, 2011. Hyattsville, MD: US

Department of Health and Human Services, Centers for Disease Control and Prevention, National Center for Health Statistics; 2012. http://www.cdc.gov/nchs/hus/contents2011.htm\#03 1

9. US Department of Health and Human Services, Administration on Aging. A profile of older Americans: 2011. http://www.aoa.gov/AoAroot/Aging Statistics/Profile/2011/docs/2011profile.pdf.

10. Schiller JS, Lucas JW, Ward BW, Peregoy JA. Summary health statistics for U.S. adults: National Health Interview Survey, 2010. Vital Health Stat 10. 2012 ;(252):1-207.

11. Swain S, Turner C, Tyrrell P, Rudd A: Diagnosis and initital management of acute stroke and transient ischaemic attack: summary of NICE guidance. BMJ2008, 337:786

12. Jauch EC, Saver JL, Adams Jr HP, Bruno A, Connors JJ, Demaerschalk BM, et al. Guidelines for the early management of patients with acute ischemic stroke: a guideline for healthcare professionals from the American Heart Association/American Stroke Association. Stroke. 2013; 44(3):870-947 
13. V.L.Feigin, M.H.Forouzanfar, R.Krishnamurthi et al., "Global and regional burden of stroke during1990-2010:findings from the Global Burden of Disease Study 2010," The lancet. 2014; 383: 245-255

14. World Health Organisation (WHO). Fact sheet No. 311http://www.who.int/mediacentre/factsheets/fs31 1/en/ (2011).(Last accessed 2018 March14)

15. World Health Organisation (WHO). Cardiovascular Diseases Fact Sheet No 317.Geneva,http:// www.who.int/mediacentre/factsheets/fs317/en/ (2011). (Last accessed 2018 March 14)

16. G.A.Mensah, "Epidemiology of stroke and high blood pressure in Africa,"Heart, 2008; 94(6): 697-705

17. Shah M, Makinde KA, Thomas P: Cognitive and behavioral aspects affecting early referral of acute stroke patients to hospital. Journal of Stroke \&Cerebrovasc Dis 2007, 16(2):71-76.

18. Boden-Albala B, Carman H, Moran M, Doyle M, Paik MC. Perception of recurrent stroke risk among black, white and Hispanic ischemic stroke and transient ischemic attack survivors: the SWIFT study. Neuroepidem.2011; 37:83-87.

19. Chao J, Wang Y, Xu H, Yu Q, Jiang L, Tian L, et al. The effect of community-based health management on the health of the elderly: A randomized controlled trial from China. BMC Health Services Res 2012; 12:449.

20. Pandian JD, Jaison A, Deepak SS, Kalra G, Shamsher S, Lincoln DJ, et al. Public Awareness of Warning Symptoms, RiskFactors, and Treatment of Stroke in Northwest India. Stroke, 2005, 36:644-8

21. Pancioli AM, Broderick J, Kothari R, Brott T, Tuchfarber A, Miller R, Khoury J, Jauch E: Public perception of stroke warning signsand knowledge of potential risk factors. JAMA1998, 279:12881292.

22. Yoon SS, Byles J: Perceptions of stroke in the general publicand patients with stroke: a qualitative study. BMJ2002, 324:1065-1070.

23. Samsa GP, Cohen SJ, Goldstein LB, Bonito AJ, Duncan PW, Enarson C, et al. Knowledge of riskamong patients at increased risk for stroke. Stroke1997, 28:916-921.

24. Kothari R, Sauerbeck L, Jauch E, Broderick J, Brott $\mathrm{T}$, Khoury J,et al. Patients' awareness of stroke signs, symptoms and risk factors.Stroke1997, 28:1871-75.

25. Gupta TP. Knowledge of stroke symptoms and risk factors among at risk elderly patients in the U. K. Inter J of Clin Prac 2002; 56: 634-637

26. Bennett S, Woods T, Liyanage WM, Smith DL. A simplified general method for cluster-sample surveys of health in developing countries. World Health Stat Q.1991; 44:98-106

27. Cox EO, Dooley A, Liston M, Miller M. Coping with stroke: perceptions of elderly who have experienced stroke and rehabilitation interventions. Top Stroke Rehabil 1998; 4: 76-88.

28. Mandelzweig L, Goldbourt U, Boyko V, Tanne D. Perceptual, social, and behavioral factors associated with delays in seeking medical care in patients with symptoms of acute stroke. Stroke. 2006; 37: 1248-53.

29. Carroll C, Hobart J, Fox C, Teare L, Gibson J: Stroke in Devon: knowledge was good, but action was poor. J Neuro, Neurosur \& Psych2004, 75(4):567-571.

30. Giles MF, Flossman E, Rothwell PM: Patient behavior immediately after transient ischemic attack according to clinical characteristics, perception of the event, and predicted risk of stroke. Stroke2006, 37(5):1254-1260.

31. Chang KC, Tseng MC, Tan TY. Prehospital delay after acute stroke in Kaohsiung, Taiwan. Stroke. 2004; 35 (3):700-4.

32. Jurkowski JM, Maniccia DM, Denninson BA, Samuels SJ, Spicer DA. Awareness of necessity to call 911 for stroke symptoms, upstate New York. Prev Chronic Dis2008; 5(20): A41.

33. Mosley I, Nicol M, Donnan G, Patrick I, Dewey H. Stroke symptoms and the decision to call for an ambulance. Stroke. 2007; 38 (2):361-6.

34. Bandura A. Social foundations of thought and action: a social cognitive theory. Englewood Cliffs, NJ: Prentice Hall, 1986

35. Kreuter MW, Strecher VJ. Changing inaccurate perceptions of health risk: results from a randomized trial. Health Psychol. 1995; 14:56-63

36. Natasha M, Kathryn MM, John FS, Nicola MK. Help-seeking at the time of stroke: stroke survivors' perspectives on their decisions. Health \& Social Care in the Community. 2008; 16:501-510. 
37. Reeves MJ, Hogan JG, Rafferty AP: Knowledge of stroke risk factors and warning signs among Michigan adults. Neurology 2002, 59(10): 15471552.

38. Jones SP, Jenkinson AJ, Leathley MJ, Watkins CL. Stroke knowledge and awareness: an integrative review of the evidence. Age Ageing. 2010; 39:11-22.

39. Kwan J, Hand P, Sandercock P. A systematic review of barriers to delivery of thrombolysis for acute stroke. Age Ageing. 2004; 33(4):116-21

40. Pontes-Neto OM, Silva GS, Feitosa MR, de Figueiredo NL, Fiorot JA Jr, RochaTN, et al. Stroke awareness in Brazil: alarming results in a community-based study. Stroke. 2008; 39:292-296.

41. Madsen TE, Baird KA, Silver B, Gjelsvik A. Analysis of gender differences in knowledge of stroke warning signs. J Stroke Cerebrovasc Dis. 2015; 24:1540-7.

42. Stroebele N, Müller-Riemenschneider F, Nolte CH, Müller-Nordhorn J, Bockelbrink A, Willich SN. Knowledge of risk factors, and warning signs of stroke: a systematic review from a gender perspective. Int J Stroke. 2011; 6:60-6.

43. The Lancet Neurology. Sex differences and stroke prevention. LancetNeurol.2014; 13(4):339-438

44. Foerch C, Misselwitz B, Humpich M, Steinmetz H, Neumann-Haefelin T,

Sitzer M, for the Arbeitsgruppe Schlaganfall Hessen. Sex disparity in theaccess of elderly patients to acute stroke care. Stroke. 2007; 38:2123-6.

45. Sacco RL. Toward optimal health: A renewed look at stroke in women. Interview by Jodi R. Godfrey. J Womens Health (Larchmt). 2009; 18:13-18.

46. Haast RA, Gustafson DR, Kiliaan AJ. Sex differences in stroke. J Cereb Blood Flow Metab. 2012; 32:2100-2107.

47. Mouradian MS, Majumdar SR, SenthilselvanA, Khan K, Shuaib A. How well are hypertension, hyperlipidemia, diabetes, and smoking managed after a stroke or transient ischemic attack? Stroke 2002; 33: 1656-1659.

48. Raine R, Wong W, Ambler G, Hardoon S, Petersen $\mathrm{I}$, Morris R, et al.Examination of socio-demographic variations in the contribution of secondary drug prevention to stroke survival at middle and older ages. BMJ 2009; 338: b1279.

49. O'Carroll, R, Whittaker, J, Hamilton, B, Johnston, M, Sudlow, C \& Dennis, M Predictors of adherence to secondary preventive medication in stroke patients. Ann Behav Med 2011; 41: 383-390.

50. Sjo“" lander M, Eriksson M and Glader E-L. The association between patients' beliefs about medicines and adherence to drug treatment after stroke: A cross-sectional questionnaire survey. BMJ Open 2013; 3.

51. Xu J, Ju Y, Wang $C$, Wang Y, Liu L, Zhao X, et al. Patterns and predictors of antihypertensive medication used 1 year after ischemic stroke or TIA in urban China. Patient. Prefer Adher2013; 7 : 71-79. 